\title{
FUNCTIONAL INEQUALITIES FOR INCOMPLETE GAMMA AND RELATED FUNCTIONS
}

\author{
MOURAD E. H. ISMAIL AND ANDREA LAFORGIA
}

Abstract. For the incomplete gamma function and related functionse we establish functional inequalities of the type $f(x) f(y)-f(x+y) \geqslant 0$ for all $x, y \in(0, \infty)$.

Mathematics subject classification (2000): 33B15, 33C05.

Key words and phrases: incomplete gamma function, inequalities, error function.

\section{REFERENCES}

[1] H. ALZER, Functional inequality for the error function, to appear.

[2] G. E. ANDREWs, R. A. AskeY, AND R. RoY, Special Functions, Cambridge University Press, Cambridge, 1999.

[3] G. Gasper, M. Rahman, Basic Hypergeometric Series, Cambridge University Press, Cambridge, 1990.

[4] W. GAUTSCHI, The incomplete gamma function since Tricomi, in "Tricomi's ideas and contemporary applied mathematics, (Rome/Turin, 1977)", Atti. Convegni Lincei, 147, Accad. Naz. Lincei, Rome, 1998, 203-237.

[5] D. S. Mitronović, Analytic Inequalites, Springer-Verlag, 1970. 